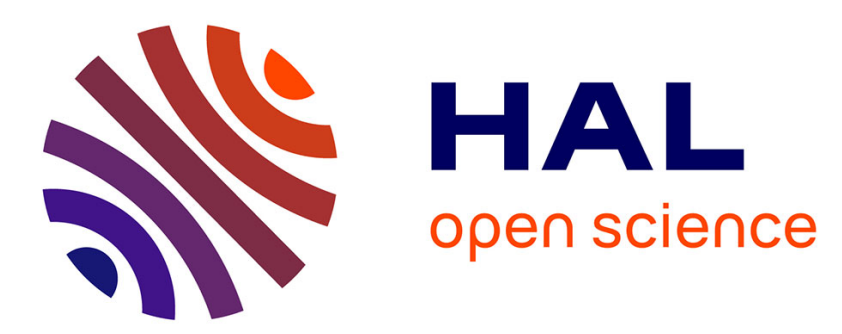

\title{
Impact of high Saharan dust inputs on dissolved iron distributions in the Mediterranean Sea.
}

Cécile Guieu, Yann Bozec, Stéphane Blain, Céline Ridame, Géraldine

Sarthou, Nathalie Leblond

\section{To cite this version:}

Cécile Guieu, Yann Bozec, Stéphane Blain, Céline Ridame, Géraldine Sarthou, et al.. Impact of high Saharan dust inputs on dissolved iron distributions in the Mediterranean Sea.. Geophysical Research Letters, 2002, 29 (19), pp.17-1-17-4. 10.1029/2001GL014454 . hal-00166825

\section{HAL Id: hal-00166825 \\ https://hal.science/hal-00166825}

Submitted on 26 Jan 2021

HAL is a multi-disciplinary open access archive for the deposit and dissemination of scientific research documents, whether they are published or not. The documents may come from teaching and research institutions in France or abroad, or from public or private research centers.
L'archive ouverte pluridisciplinaire $\mathbf{H A L}$, est destinée au dépôt et à la diffusion de documents scientifiques de niveau recherche, publiés ou non, émanant des établissements d'enseignement et de recherche français ou étrangers, des laboratoires publics ou privés. 


\title{
Impact of high Saharan dust inputs on dissolved iron concentrations in the Mediterranean Sea
}

\author{
C. Guieu, ${ }^{1}$ Y. Bozec, ${ }^{2,3}$ S. Blain, ${ }^{2}$ C. Ridame, ${ }^{1}$ G. Sarthou, ${ }^{2}$ and N. Leblond ${ }^{1}$ \\ Received 26 November 2001; accepted 5 February 2002; published 5 October 2002.
}

[1] During the PROSOPE cruise (Sept. 1999) in the Mediterranean Sea, dissolved iron concentrations in seawater and iron and aluminium concentrations in aerosols collected on board were investigated. Concentrations in aerosols were about two times higher in the Tyrrhenian Sea than in the west (Alboran Sea). This was in good agreement with the observed increase in dissolved iron concentrations in the surface waters from West to East. Depth profiles were characterised by a maximum in the surface mixed layer. Using an in vitro experiment, iron released from Saharan dust during the season characterized by a stratified water column and a low primary productivity was estimated: it resulted in an accumulation of $0.5-0.8 \mathrm{nM}$ dissolved iron, in good agreement with the observed iron enrichment in the surface water $(0.8 \mathrm{nM})$. This study confirms the significance of atmospheric input of Saharan origin on the iron cycle in the Mediterranean Sea. INDEX TERMS: 1065 Geochemistry: Trace elements (3670); 1050 Geochemistry: Marine geochemistry (4835, 4850); 0305 Atmospheric Composition and Structure: Aerosols and particles $(0345,4801)$. Citation: Guieu, C., Y. Bozec, S. Blain, C. Ridame, G. Sarthou, and N. Leblond, Impact of high Saharan dust inputs on dissolved iron concentrations in the Mediterranean Sea, Geophys. Res. Lett., 29(19), 1911, doi:10.1029/ 2001GL014454, 2002.

\section{Introduction}

[2] The Mediterranean sea is strongly influenced by atmospheric inputs into the water column. This is due first to the close vicinity of the Saharan desert, which provides a source for considerable amounts of dust, and second to the strong stratification of the surface water column during a large part of the year which dramatically reduces exchange between surface and deep waters.

[3] Input of Saharan material represents approximately $90 \%$ of the total atmospheric particulate fallout to the water column [Loÿe-Pilot et al., 1986] and is a major source of elements of biogeochemical importance such as iron $(\mathrm{Fe})$. Indeed in the Western Mediterranean, Fe associated with Saharan dust represents $96 \%$ of the total atmospheric flux of $\mathrm{Fe}$ and Saharan dust is the main source of dissolved iron [Guieu et al., 2002]. During the period of water column stratification in this area (June-October), the strong strat-

\footnotetext{
${ }^{1}$ Laboratoire d'Océanographie de Villefranche-sur-Mer (LOV), CNRS, Villefranche-sur-Mer, France.

${ }^{2}$ Laboratoire des sciences de l'environnement marin (LEMAR), Institut Universitaire Européen de la mer, Plouzané France.

${ }^{3}$ Now at Netherlands Institute for Sea Research (NIOZ), Department of Marine Chemistry and Geology, Texel, The Netherlands.
}

Copyright 2002 by the American Geophysical Union. 0094-8276/02/2001GL014454 ification and the low surface production may allow atmospheric iron to accumulate in the surface mixed layer [Sarthou and Jeandel, 2001]. In contrast, after the spring bloom of phytoplankton, and in the absence of any Saharan dust input, the surface mixed layer can become Fe-depleted, with concentrations lower than $0.1 \mathrm{nM}$ [Sarthou and Jeandel, 2001].

[4] The aim of this study was to investigate the effect of strong atmospheric inputs on the dissolved iron concentrations in the Mediterranean Sea.

\section{Material and Methods}

\subsection{Water and Aerosol Sampling}

[5] Samples were collected on board R/V Thalassa during the PROSOPE cruise (PROductivity of PElagic Oceanic Systems). The cruise took place from 4 September (Agadir, Morocco) to 4 October (Toulon, France) 1999. The cruise track can be seen in Clauster et al., 2002.

\subsubsection{Aerosols sampling}

[6] Aerosol sampling was performed while the ship was underway while exhaust fumes were not blowing across the sampler to avoid any contamination. A small volume pump (Reciprotor AB, Sweden) was connected to a polycarbonate filter holder (Sartorius) installed at the front of the ship fourteen meters above sea level. Nuclepore filters $(0.4-\mu \mathrm{m}$ pore diameter, $47 \mathrm{~mm}$ ) were installed (removed) on (from) the filter holder inside the clean container. Collected air volume varying between 14 and $25 \mathrm{~m}^{3}$.

\subsubsection{Water sampling}

[7] Water samples were collected throughout the water column $(0-2000 \mathrm{~m})$ at two 5-day drifting stations (MIO, $33^{\circ} 58 \mathrm{~N}, 22^{\circ} 00 \mathrm{E}$ and DYFAMED, $\left.43^{\circ} 22 \mathrm{~N}, 7^{\circ} 52 \mathrm{E}\right)$; surface samples were collected at two different depths $(5 \mathrm{~m}$ and 10 m) at eight 4-hour stations. In the upper $200 \mathrm{~m}$, a Teflon pump was connected to polyethylene tube attached to a Kevlar cable and used for sampling. In-line filtration (Nuclepore $0.4 \mu \mathrm{m}$ pore diameter, $47 \mathrm{~mm}$ ) was performed in a laminar flow hood (class 100) in a clean laboratory container. Below $200 \mathrm{~m}$, samples were taken from clean Niskin bottles and filtered immediately inside the clean container. The filtered samples were acidified on board to pH 2.0 with $\mathrm{HNO}_{3}$ (Suprapur Merck) and stored in acid washed high-density polyethylene bottles.

\subsection{Iron Analysis}

\subsubsection{Particulate iron and aluminium}

[8] Aerosol samples were acid-digested inside a Milestone 1200 Mega microwave oven with $1 \mathrm{ml}$ of HF and $3 \mathrm{ml}$ of $\mathrm{HNO}_{3}$ (Suprapur, Merck). $\mathrm{Al}$ and $\mathrm{Fe}$ were analysed in digested samples by Inductively Coupled Plasma-Atomic Emission Spectroscopy (ICP-AES, 'Ultra Trace', Jobin Yvon) and concentrations determined using calibration 
Table 1. Elemental Concentrations in Aerosol Samples During the PROSOPE Cuise

\begin{tabular}{ccccc}
\hline $\begin{array}{c}\text { Filter sample } \\
\text { number }\end{array}$ & $\begin{array}{c}\text { Collected } \\
\text { between: }\end{array}$ & $\begin{array}{c}\mathrm{Fe} \\
\mu \mathrm{g} \mathrm{m}^{-3}\end{array}$ & $\begin{array}{c}\mathrm{Al} \\
\mu \mathrm{g} \mathrm{m}^{-3}\end{array}$ & $\begin{array}{c}\mathrm{Fe} / \mathrm{Al} \\
\mu \mathrm{g} / \mu \mathrm{g}\end{array}$ \\
\hline AERO-5 & St.1-St.2 & 0.14 & 0.36 & 0.4 \\
AERO-6 & St.2-St.3 & 0.44 & 0.75 & 0.6 \\
AERO-7 & St.3-St.4 & 0.24 & 0.44 & 0.6 \\
AERO-8 & St.4-St.5 & 0.14 & 0.28 & 0.5 \\
AERO-9 & St.5-St.6 & 0.21 & 0.14 & 1.5 \\
AERO-10 & St.6-St.7 & 0.13 & 0.19 & 0.7 \\
AERO-11 & St.7-St.8 & 1.07 & 1.94 & 0.6 \\
AERO-12 & St.8-St.9 & 0.35 & 0.54 & 0.6 \\
\hline
\end{tabular}

Aerosol sampling was performed while the ship was underway between two stations.

graphs. Blanks (reagents alone and reagents + blank filter) were below the detection limit. Recovery obtained on a certified reference material (MESS, National Research Council of Canada) were: $\mathrm{Al}=92 \% \pm 3 \%(\mathrm{n}=6) ; \mathrm{Fe}=101 \% \pm 2 \%$ $(\mathrm{n}=6)$ ), indicating a good accuracy of the digestion/analysis. 2.2.2. Dissolved iron

[9] Dissolved iron was analysed according to a chemiluminescent method adapted from Obata et al. [1993] [see Bucciarelli et al., 2001]. Calibration curves were performed using known iron additions in oceanic samples with low iron concentrations (that were below the detection limit). The detection limit (3 standard deviations of 10 replicates of blank) was $0.14 \mathrm{nM}$. Accuracy of the method was assessed using the international reference material: NASS-5 (North Atlantic Surface Seawater, National Research Council of Canada): $3.69 \pm 0.62 \mathrm{nM}$ certified value, $3.60 \pm 0.04 \mathrm{nM}$ determined.

\subsection{Dissolution Experiment}

[10] Saharan soil was used to perform the in vitro experiments in place of Saharan aerosols. This soil was representative of the Saharan aerosol transported over the Mediterranean. [Guieu et al., 2002]. Various amounts of Saharan soil were introduced into ultra-pure water in order

Table 2. Dissolved Iron Concentrations (nM) During the PROSOPE Campaign

\begin{tabular}{|c|c|c|c|c|c|c|}
\hline \multicolumn{4}{|c|}{ Long occupation stations } & \multicolumn{3}{|c|}{ Short occupation Stations } \\
\hline \multicolumn{2}{|c|}{ 'MIO' } & \multicolumn{2}{|c|}{ ‘DYFAMED’ } & \multirow[b]{2}{*}{ site } & \multirow[b]{2}{*}{ depth } & \multirow[b]{2}{*}{$\mathrm{Fe}$} \\
\hline depth & $\mathrm{Fe}$ & depth & $\mathrm{Fe}$ & & & \\
\hline & & & & 2 & 5 & 1.17 \\
\hline 5 & 1.46 & 5 & 1.42 & 2 & 10 & 0.70 \\
\hline 10 & 1.99 & 9 & 1.23 & 3 & 5 & 1.09 \\
\hline 24 & 0.59 & 20 & $3.1^{*}$ & 3 & 10 & 0.93 \\
\hline 50 & 0.61 & 40 & 0.45 & 4 & 5 & 1.79 \\
\hline 75 & 0.42 & 73 & 0.47 & 4 & 10 & 1.93 \\
\hline 102 & 0.26 & 99 & 0.39 & 5 & 5 & 2.59 \\
\hline 124 & 0.28 & 124 & 0.60 & 5 & 10 & 2.00 \\
\hline 145 & 0.36 & 150 & 0.62 & 6 & 5 & 1.54 \\
\hline 175 & $13.5^{*}$ & 173 & 0.51 & 6 & 10 & 2.00 \\
\hline 188 & 1.08 & 193 & 0.57 & 7 & 5 & 1.77 \\
\hline 200 & 0.78 & 200 & $3.5^{*}$ & 7 & 10 & 2.72 \\
\hline 450 & 0.59 & 450 & 1.08 & 8 & 5 & 2.54 \\
\hline 1000 & 0.13 & 1000 & 1.06 & 8 & 10 & 1.60 \\
\hline \multirow[t]{2}{*}{2000} & 0.33 & 2000 & 0.52 & 9 & 5 & 1.50 \\
\hline & & & & 9 & 10 & 2.70 \\
\hline
\end{tabular}

Depth in dba.

The data labelled $(*)$ are suspected to be contaminated.

Crosses denote the sampling mode used. to mimic dissolution processes occurring during a Saharan dust event. The experiment is fully described in Ridame and Guieu, [2002] and results are issued from Ridame, [2001].

\section{Results}

\subsection{Iron Concentrations}

\subsubsection{Aerosols concentrations}

[11] Aerosols concentrations ranged between 0.13-1.07 $\mu \mathrm{g} . \mathrm{m}^{-3}$ for iron and $0.14-1.94 \mu \mathrm{g} . \mathrm{m}^{-3}$ for aluminum (Table 1). The highest concentrations were found in the central part of the western Mediterranean (between station 2 and 4) and during the transect between MIO and DYFAMED.

\subsubsection{Dissolved iron}

[12] Dissolved iron concentrations (Table 2) ranged from 0.26 to $2.72 \mathrm{nM}$ in the upper $200 \mathrm{~m}$. These concentrations are generally higher than concentrations in open ocean waters and are consistent with previously published values in the same area [Sarthou and Jeandel, 2001, and references therein]; In deep waters, concentrations varied between 0.13 and $1.08 \mathrm{nM}$ and are typical of open ocean ones [Johnson et al., 1997].

[13] The upper water column was strongly stratified with a surface mixed layer of $20-30 \mathrm{~m}$. The vertical profiles of dissolved iron in the upper $150 \mathrm{~m}$ were quite similar at stations MIO and DYFAMED (Figure 1). Maximum surface concentrations of $1.75 \pm 0.35 \mathrm{nM}(\mathrm{n}=2)$ and $1.30 \pm 0.10 \mathrm{nM}$ $(n=2)$ were observed at stations MIO and DYFAMED, respectively. Below the thermocline, concentrations decreased rapidly and remained constant up to $150 \mathrm{~m}$ $(0.42 \pm 0.15 \mathrm{nM}$ at MIO and $0.51 \pm 0.10 \mathrm{nM}$ at DYFAMED)

[14] Below $150 \mathrm{~m}$, the dissolved iron concentration increased up to a maximum of $1 \mathrm{nM}$ (Figure 2). The depths of the iron maximum are different at both stations (200 $\mathrm{m}$ at MIO and around $400 \mathrm{~m}$ at DYFAMED), but are consistent with the depths of the maximum of salinity characterizing the Levantine Intermediate Water (LIW). At $2000 \mathrm{~m}$, concentrations are equal to 0.33 and $0.52 \mathrm{nM}$ at $\mathrm{MIO}$ and DYFAMED, respectively.
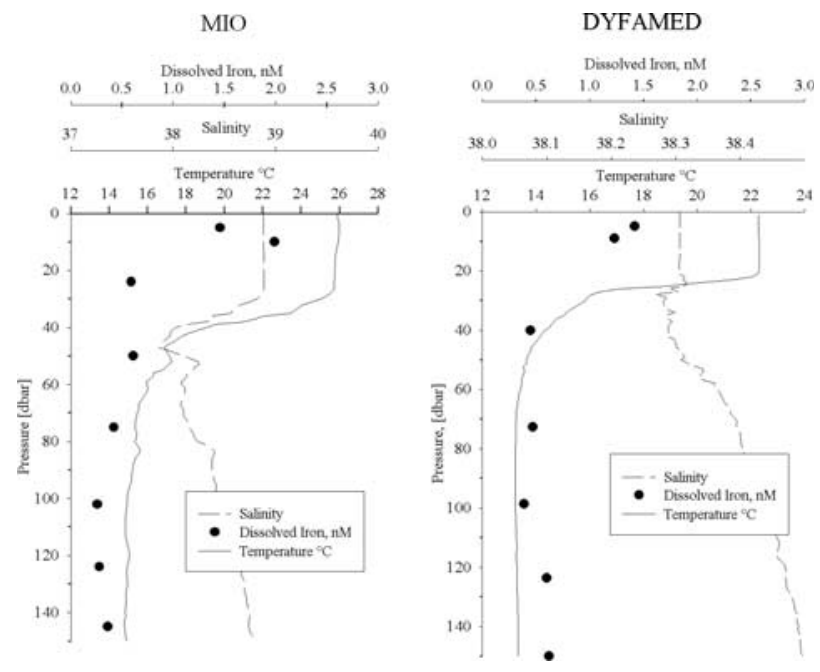

Figure 1. Depth profiles of temperature $\left({ }^{\circ} \mathrm{C}\right)$, salinity and dissolved iron (nM) in the upper $150 \mathrm{~m}$ at stations MIO (a) and DYFAMED (b). 

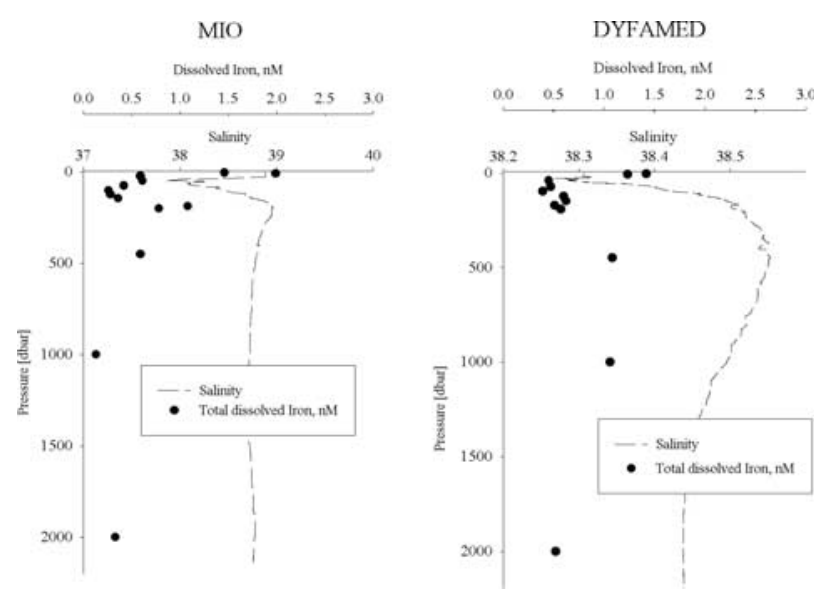

Figure 2. Depths profiles $(0-2000 \mathrm{~m})$ of salinity and dissolved iron (nM) at stations MIO(a) and DYFAMED (b).

[15] In the surface mixed layer, the highest dissolved iron concentrations $(\sim 2-2.5 \mathrm{nM})$ were found at stations $5,7,8$ and 9 located in the Tyrrhenian Sea and/or close to Sicily. The lowest concentrations $(\sim 1 \mathrm{nM})$ were found in the western Mediterranean (stations 2, 3). The average dissolved iron concentrations in the surface mixed layer gradually increased from west to east.

\subsection{Dissolution Experiment}

[16] The percentage of iron released in pure water by Saharan dust as a function of the amount of dust added is shown in Figure 3. The highest dissolution $(0.24 \%)$ was observed with the lowest amount of dust $\left(5 \mathrm{mg} \mathrm{l}^{-1}\right)$. The percentage of iron released from the dust decreased for higher particulate loads following a logarithmic law.

[17] The experiment described above was conducted to mimic the dissolution process in rainwater and the logarithmic law can be applied knowing the amount of dust (mg $1^{-1}$ ) measured for a Saharan rain. For the events with no measurable rainfall (dust is deposited with only few drops of rainwater, the raindrops are evaporated immediately and all the dissolution will occur in seawater), the same dissolution law can be used, in a first approximation, to evaluate the amount of dissolved iron released from the particles in the water column. This approach is a first approximation as dissolution in ultra-pure water is not representative of dissolution processes that may occur in seawater. Indeed, the lower ionic strength of ultra-pure water and the absence of ligands may lead to an underestimation of the amount of dissolved iron released. On the other hand, the solubility of iron is related strongly to $\mathrm{pH}$ [Guieu and Thomas, 1996] and at pH 7 (pH resulting from Saharan dust addition in pure-water), Fe is more soluble than at seawater $\mathrm{pH}$. Thus, this approach has to be considered as a rough estimate of the amount of dissolved iron released in seawater from these particular events that can not be considered as dry deposition.

\section{Discussion}

[18] During the campaign, sampled aerosols exhibited strong variations in $\mathrm{Fe}$ and $\mathrm{Al}$ concentrations. From direct observation onboard, and satellite imagery (not shown), as the ship was traversing between stations 2 and 4, a Saharan dust plume was entering the Mediterranean atmosphere. Concentrations reported for the two corresponding samples (Table 1: AERO 6 and 7) exhibit an Fe/Al ratio very similar to the one determined for the Saharan end-member $(0.63 \pm$ 0.02, Guieu et al., 2002). Two additional samples are thought to reflect a Saharan origin (AERO 11 and 12): they were collected in the Tyrrhenian Sea and exhibit high concentrations in both $\mathrm{Fe}$ and $\mathrm{Al}$, comparable to the values reported by Chester et al., [1984] for Saharan aerosols collected in the same area. For these two samples, the Fe/ Al ratio is also representative of the Saharan end-member. Indeed, for these samples, the three-dimensional, four-day air mass back trajectories calculated by Meteo France at surface level (not shown) indicated a transport from the south-west close to the Libyan coastal area. Aerosol iron concentrations were about two times higher in the Tyrrhenian Sea than in the west (Alboran Sea). This may explain the increase in dissolved iron concentrations from West to East in the surface mixed layer.

[19] Dissolved iron depth profiles at stations MIO and DYFAMED indicate a significant enrichment in the surface waters. During the period of water column stratification, the surface mixed layer is isolated from deeper waters, and the atmosphere is the main source of nutrients such as iron and phosphorus to the surface waters [see for example, Ridame and Guieu, 2002]. The strong stratification and the low surface production should allow the atmospheric input of dissolved iron to accumulate in the mixed layer.

[20] At the DYFAMED station, the observed iron enrichment in the surface layer was equal to $0.8 \mathrm{nM}$ [i.e., $1.3_{\text {(surface }}$

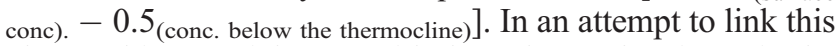
observed iron enrichment with the Saharan dust input in the central Ligurian Sea, we have calculated from the dissolution experiments, the dissolved iron concentrations which may result from the Saharan dust input measured at two coastal sites of the Ligurian Sea.

[21] In 1999, from June to the end of September (end of the PROSOPE cruise), a total dust flux of $2.4 \mathrm{t} \mathrm{km}^{-2}$ was recorded at Villefranche-sur-Mer [Ridame and Guieu, 2002] while a total dust flux of $5.9 \mathrm{t} \mathrm{km}^{-2}$ was recorded in Corsica (Loÿe-Pilot, pers. com). Considering that the Saharan dust is characterised by a total iron concentration of $4.5 \%$ [Guieu et $a l ., 2002]$, the Saharan source represented, from June to end

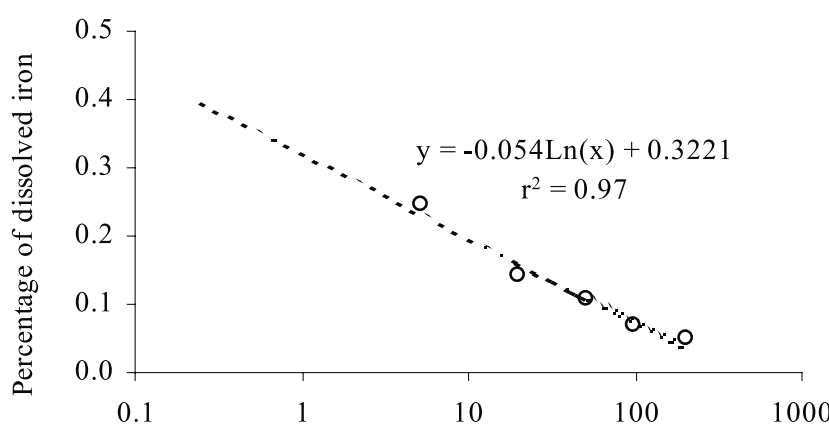

Amount of Saharan dust introduced in the water, $\mathrm{mg}^{-1}$

Figure 3. Percentage of dissolved iron vs. the quantity of Saharan dust (in $\mathrm{mg} \mathrm{l}^{-1}$ ) introduced in ultrapure water (see text for the experimental protocol). 
of September, a total iron flux of $193 \times 10^{4}-475 \times 10^{4}$ nmol. $\mathrm{m}^{-2}$. During the considered period, all dust deposition came with wet deposition with a high proportion of events with no measurable rainfall. The calculated (from the dissolution law) dissolution percentage in rains (with measurable rainfall) ranged from $0.05 \%$ to $0.3 \%$. The total amount of dissolved iron released was then calculated by summing the estimated amounts of dissolved iron carried by individual events. For the events with no measurable rainfall, the dissolution in rainwater can be considered as negligible and the main dissolution process will occur in seawater [Ridame and Guieu, 2002]. Because more than 60 to $\sim 90 \%$ of these particles have a median diameter below 1 m [Chester and Johnson, 1971; Guieu et al., 2002], the residence time, of these particles, in the surface layer is long. Based on Stokes law, the sedimentation rate of the mineral particles in seawater can be computed as a function of particle size: a size-fraction lower than $1 \mu \mathrm{m}$ settle at rates $\leq 5 \mathrm{~cm}^{-1}$ [Ry $^{-1}$ [Ridame and Guieu, 2002]. Consequently, these fine particles will accumulate in the surface layer during the entire stratified period while dissolution processes occur. The dust flux $\left(\mathrm{mg} \mathrm{m}^{-2}\right)$ actually measured for each of these events has been assumed to disperse over the upper 15-20 m surface layer; from the corresponding particle concentration in seawater (in $\mathrm{mg}$ $1^{-1}$ ), the percentage of dissolution was deduced from the logarithmic law (section 3.2). The obtained dissolution percentage ranged from 0.4 to $0.6 \%$.

[22] These values are of the same order of magnitude as values reported in the literature [Jickells and Spokes, 2001 and references within] for crustal aerosol. It is one order of magnitude higher than the previous estimation of Guieu and Thomas [1996]. This discrepancy results from the larger grain size of the desert soil used by Guieu and Thomas [1996].

[23] The total dissolved concentration from atmospheric input that is predicted to accumulate in the surface mixed layer $(15-20 \mathrm{~m})$ was then calculated as the sum of the iron released in rainwater and in seawater: it varied between 0.5 and $0.8 \mathrm{nM}$.

[24] This calculation is an upper limit, as it assumes that the residence time of iron is longer than the oligotrophic period and because we consider negligible effects of phytoplankton uptake, scavenging and physical mixing in the surface mixed layer during this period.

[25] This estimation is in good agreement with the observed dissolved iron accumulation $(0.8 \mathrm{nM})$ and supports the atmospheric origin from Sahara of the iron enrichment observed in the Mediterranean Surface Water.

[26] The other important feature of the iron profiles at DYFAMED and MIO stations is the deep iron maximum related to the occurrence of the LIW. The LIW results from sinking of Mediterranean Surface Water in the eastern part of the basin. The LIW flows back to the west at intermediate depths. The deep iron maximum may be the fingerprint of the surface origin of the water masses, which is consistent with the deepening of the maximum between $\mathrm{MIO}$ and DYFAMED.
[27] This study confirms the significance of the atmospheric input of dust of Saharan origin on the iron cycle in the Mediterranean Sea. Further investigations are currently in progress with regard to the impact of these inputs on the biological functioning of the Mediterranean Sea, in particular during the season characterized by a stratified water column and low primary productivity.

[28] Acknowledgments. The captain and the crew of the RV Thalassa and H. Claustre are gratefully acknowledged. The authors thank M.D. Loÿe-Pilot for data of Saharan flux measured in Corsica, D. Tailliez for providing the CTD data and M. Lewis for his help with the English. The helpful comments of the two anonymous reviewers are gratefully acknowledged.

\section{References}

Bucciarelli, E., S. Blain, and P. Tréguer, Iron and manganese in the wake of the Kerguelen Islands (Southern Ocean), Mar. Chem., 73(1), 21-36, 2001.

Chester, R., and L. R. Johnson, Atmospheric dusts collected off the Atlantic coasts of North Africa and the Iberian peninsula, Marine Geol., 11, 251260, 1971

Chester, R., E. J. Sharples, and G. S. Sanders, Saharan dust incursion over the Tyrrhenian Sea, Atmospheric Environment, 18, 5929-5935, 1984.

Claustre, H., A. Morel, S. B. Hooker, M. Babin, D. Antoine, K. Oubelkheir, A. Bricaud, K. Léblanc, B. Quéguiner, and S. Maritorena, Is desert dust making oligotrophic waters greener?, Geophys. Res. Lett., 29, 10.1029/ 2001GL014056, 2002.

Guieu, C., and A. J. Thomas, Saharan aerosols: from the soil to the ocean, in The Impact of desert dust across the Mediterranean, edited by S. Guerzoni and R. Chester, 207-216, Kluwer Acad. Publ., 1996.

Guieu, C., M.-D. Loye-pilot, C. Ridame, and C. Thomas, Chemical characterization of the Saharan dust end-member; some biological implications for the western Mediterranean, Journal of Geophysical Research, 10.1029/2001JD000582, 2002.

Jickells, T., and L. J. Spokes, Atmospheric iron inputs to the oceans, in The biogeochemisry of Iron in seawater, edited by D. R. Turner and K. A. Hunter, SCOR-IUPAC, Baltimore, Wiley \& Sons, Inc., 85-121, 2001.

Johnson, K. S., R. M. Gordon, and K. H. Coale, What controls dissolved iron in the world ocean?, Marine Chemistry, 57, 137-161, 1997.

Loÿe-Pilot, M. D., and J. M. Martin, Saharan dust input to the Western Mediterranean: an eleven years record in Corsica, in The impact of desert dust across the Mediterranean, edited by S. Guerzoni and R. Chester, Kluwer Acad. Publ., 191-199, 1996.

Loÿe-Pilot, M. D., J. M. Martin, and J. Morelli, Influence of Saharan dust on the rain acidity and atmospheric input to the Mediterranean, Nature, 321(6068), 427-428, 1986.

Obata, H., H. Karatani, and E. Nakayama, Automated determination of iron in seawater by chelating resin concentration and chemiluminescence detection, Analytical Chemistry, 65, 1524-1528, 1993.

Ridame, Rôle des apports atmosphériques d'origine continentale dans la biogéochimie marine: Impact des apports sahariens sur la production primaire en Méditerranée, Ph. D thesis, University of Paris VI, 246 pp., 2001.

Ridame, C., and C. Guieu, Saharan input of phosphate to the oligotrophic water of the open western Mediterranean Sea, Limnology and Oceanography, 47, 856-869, 2002.

Sarthou, G., and C. Jeandel, Seasonal variations of iron concentrations in the Ligurian Sea and iron budget in the western Mediterranean, Marine Chemistry, 74, 115-129, 2001.

C. Guieu, C. Ridame, and N. Leblond, Laboratoire d'Océanographie de Villefranche-sur-Mer (LOV), CNRS, Villefranche-sur-Mer, France.

Y. Bozec, S. Blain, and G. Sarthou, Laboratoire des sciences de l'environnement marin (LEMAR), Institut Universitaire Européen de la mer, Plouzané, France. 